\title{
Preliminary results in the sexual dimorphism determination of the sea urchin Lytechinus variegatus variegatus (Lamarck, 1816), Echinoidea, Toxopneustidae
}

\author{
Denis M. S. Abessa ${ }^{1}$; Bauer R. F. Rachid ${ }^{1,2}$ \& Eduinetty Ceci Pereira M. Sousa ${ }^{1}$ \\ ${ }^{1}$ Instituto Oceanográfico da Universidade de São Paulo \\ (Caixa Postal 66149, 05315-970 São Paulo, SP, Brazil) \\ e-mail:dmabessa@usp.br \\ ${ }^{2}$ Fundação de Estudos e Pesquisas Aquáticas \\ (Av. Afrânio Peixoto, 412, 05507-000 São Paulo, SP, Brazil)
}

Sea urchin embryos are widely used as testorganisms in ecotoxicological studies. For the Southeastern Brazilian coast, chronic and acute toxicity test methods have been standardized for Lytechinus variegatus (CETESB, 1992). This species is abundant, easy to collect, and is fertile throughout the year. Moreover, tests with $L$. variegatus are sensitive, rapid and relatively easy to do. Due to these reasons, toxicity testing with this species is now routinely employed by some laboratories from the State of São Paulo.

Toxicity test protocols require the use of gamete pools obtained from at least three individuals of each sex (CETESB, 1992). Thus, for each test there is a necessity of available fertile adults in the laboratory, giving two options to the researchers: maintain them in the laboratory or use recently fieldcollected animals.

Because of long-term maintenance of $L$. variegatus in the laboratory is not easy, and also because there is a recovery time after spawning during which the animals do not have mature gametes, field collection of adults is considered the easiest method for obtaining brood stocks.

Up to date there is not any information on the sexual dimorphism of $L$. variegatus. Due to this, about 20 adults are collected for each test in order to assure that the minimum number of males and females necessary for the gamete pooling will be reached.

Spawning can be obtained by electrical $(30 \mathrm{~V}$ shock) or osmotic ( 1 to $4 \mathrm{ml} 0.5 \mathrm{~N}$ potassium chloride injection) induction. Both methods cause some stress to the animals, and common observed effects are the loss of spines and, occasionally, death. To help preventing this, the sea urchins should be transferred to tanks containing filtered seawater after use, and then returned to their respective collection sites.

$\overline{\text { Contr. no. } 845}$ do Inst. oceanogr. da Usp.
The distribution and ecology of $L$. variegatus are well described (Serafy, 1973; Giordano, 1986). According to Sánchez-Jérez et al. (2001), L. variegatus is the least abundant of the sea urchins from the State of São Paulo, occurring in areas with sand and rocks, and presenting a patchy distribution. We noticed that $L$. variegatus can be found in high densities in very few sites, and they are always present at these places, whereas in other sites they occur in variable, generally low densities or are absent. Because of this, each laboratory tend to establish regular collection sites, that are very limited both in area and number of individuals.

In recent years, the Federal and State environmental agencies actions to identify and control marine pollution have led to an increasing number of toxicity tests, and consequently to an increasing use of $L$. variegatus. Since the organisms are collected always at the same sites, this increase can represent a potential risk to such populations, as observed for Heliocidaris tuberculata in Australia (Byrne \& Laginestra, 1999). Therefore, there is an urgent need to minimize the effects of field collections of the natural populations of this species. The determination of the sexual dimorphism between males and females may reduce the number of animals induced to spawn for each test.

Although sexes are always separate in echinoids, sex-related differences are rather rare (David et al., 1988). If present, they could be more or less conspicuous and concern the size, the morphology or the genital system. More obvious cases are documented for Abatus cordatus, where the females have depressed areas on the test; Echinocyamus bisexus, where there are differences in the size and disposition of gonopores (Kier, 1968) and Echinocardium mediterraneum, where males and females present differences in the genital papillae. Tahara et al. (1960) reported that the size of gonopores of Echinocardium cordatum show sex related differences, but this assertion was made on the 
basis of a sample of 21 specimens. More recently, David et al. (1988) showed that females of $E$. cordatum have larger gonopores, but as the distribution of males and females can overlap each other, this parameter alone was not suitable for reliable determination of the sex of this sea urchin. The description of $L$. variegatus was reviewed by Mortensen (1943), without any mention to sexual dimorphism in this species. Other studies conducted since then did not show evidences of sex-related differences in L. variegatus (Serafy, 1973; Giordano, 1986).

It had already been noticed by us that among animals of the same size, females seemed to have slightly larger gonopores than males. This information, although empirical and not scientifically demonstrated, started to be used in an attempt to determine the sex of sea urchins, with a reasonable degree of success, substantially reducing the number of animals induced to spawn. As a result, the present study was designed with the objective of analyzing sexual dimorphism in the sea urchin $L$. variegatus, in order to provide information that could be used to minimize the number of animals induced to spawn for toxicity tests, thus minimizing the negative impacts on natural populations of this species.

One hundred and three individuals of $L$. variegatus were collected by snorkeling at different rocky reefs from Flamengo Bay, Ubatuba, SP, Brazil, and taken to the laboratory. The diameter and height of each sea urchin were measured upon arrival at the laboratory, by use of a micrometer. The gonopore diameter was measured under a stereomicroscope. The volume of the animals was estimated by the following procedure: each organism was left on an absorbent paper for 2 minutes in order to drain the water excess and then introduced into a graduated measuring cylinder filled with a known volume of sea water. The difference between the initial and the final water level was considered the volume of the sea urchin.

Afterwards, each animal was induced to spawn by the injection of 1 to $3 \mathrm{ml} 0.5 \mathrm{~N} \mathrm{KCl}$ (potassium chloride) into its celomatic cavity. Once the gametes were identified, the sex of the sea urchin was recorded the animal was washed with clean seawater to minimize the effects of the osmotic induction, and then introduced into a tank containing filtered seawater. At the end of the experiment all the organisms were returned to their respective collection sites.

The results were analyzed separately for males and females. The Pearson correlation analysis was applied to compare the gonopore size and the morphometric parameters, and no direct correlation was found. Therefore, a comparison between males and females was not possible.

Since the direct comparison was not possible, the animals were separated into 6 different volume classes, and for each one the mean gonopore diameter was calculated for males and females. Then the means obtained for both sexes for each volume class were compared by the paired student $\mathrm{T}$ test.

For two volume classes the differences were significant (Fig. 1): $70<$ vol. $<90 \mathrm{ml}(\mathrm{p} \leq 0.05)$ and $90<$ vol $<110 \mathrm{ml}(\mathrm{p} \leq 0.10)$. For the remaining volume classes, no significant differences were observed,

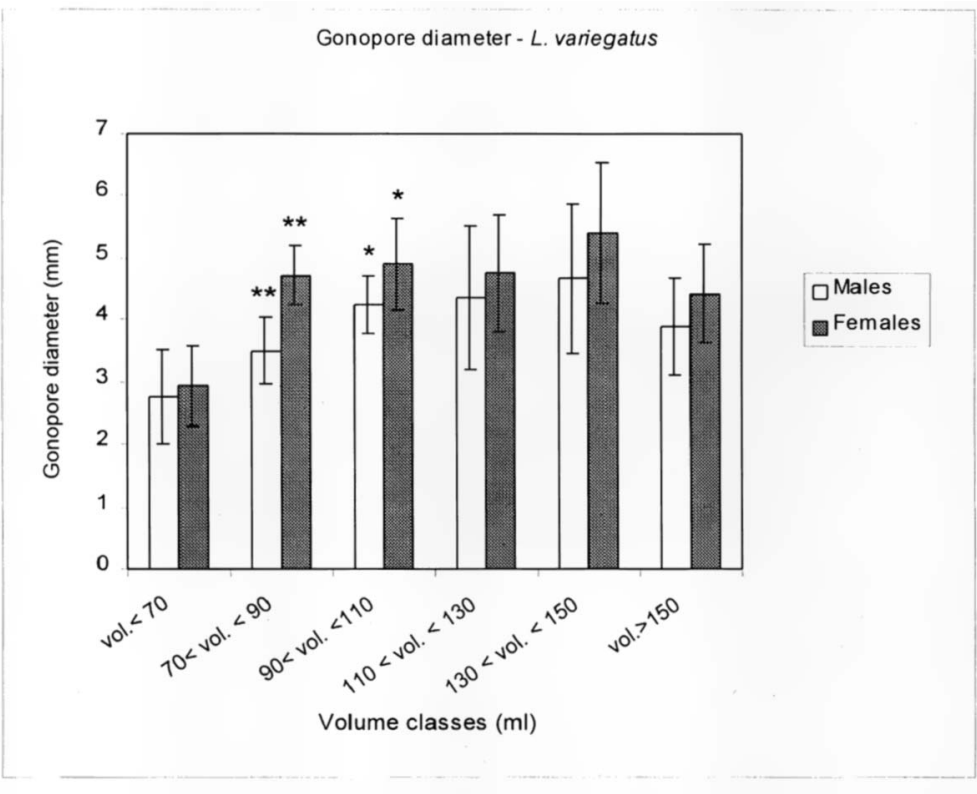

Fig. 1. Comparison of gonopore diameter between females and males of Lytechinus variegatus $(* *=$ significantly different when $\alpha<$ $0.05)(*=$ significantly different when $\alpha<0.10)$. 
although the female gonopores were always slightly larger than those from the males. This is in agreement with the observed for Echinocardium cordatum by Tahara et al. (1964) and David et al. (1988). Moreover, in the present study it was possible to observe a relation between the gonopore size and the biometry (in this case, the sea urchin volume), what was not previously reported for other species.

These results cannot be considered conclusive, since the sample number for most of the volume classes was small, ranging from 4 to 12 animals. Despite this, since females tended to have larger gonopores, the observation of volume and gonopore diameter of $L$. variegatus individuals prior their use in toxicity tests may reduce the number of organisms induced to spawn, thus reducing the potential impact of their collection on the natural populations.

\section{Acknowledgements}

To Dr Marion Nipper for the initial review and suggestions, to FAPESP (project number 98/00808-6) for the financial support and to the anonymous reviewers of this journal for the suggestions.

\section{References}

Byrne, M. \& Laginestra, E. 1999. Collection of sea urchins for toxicity testing contributes to the local decline of populations near Sydney, Australia. Setac news, 19(5):18-19.

CETESB - Companhia de Tecnologia de Saneamento Ambiental. 1992. Água do mar - Teste de toxicidade crônica de curta duração com Lytechinus variegatus, Lamarck, 1816. Norma técnica L5.250. São Paulo, CETESB. 20p.

David, B.; Laurin, B. \& De Ridder, C. 1988. How Echinocardium cordatum (Pennant) shows sexual dimorphism. In: Burke, R. D.; Mladenov, P. V.; Lambert, P. \& Parkley, R. L. eds Echinoderm biology: Proceedings of the Sixth International Echinoderm Conference. Victoria, 1987. Rotterdam, A. A. Balkema Publishers. p. 683686.
Giordano, F. L. 1986. Ouriços do sublitoral rochoso da região de São Sebastião - São Paulo. Uma abordagem ecológica. Ph.D. Thesis. UNICAMP, Instituto de Biologia. $128 \mathrm{p}$

Kier, P. M. 1968. Echinoids from the middle eocene Lake City formation of Georgia. Smithson. Misc. Coll. 153:1-45.

Mortensen, T. H. 1943. A monograph of the Echinoidea III: Camarodonta. I. Orthopsidae, Glyphocyphidae, Temnopleuridae and Toxopneustidae - Text. Copenhagen, Reitzel Publisher. 553p.

Sánchez-Jérez, P.; Cesar, A.; Cortez, F. S.; Pereira, C. S. D. \& Silva, S. L. R. 2001. Distribución espacial de las poblaciones de erizos más abundantes de la costa sudeste del litoral de São Paulo (Brasil). Ciências Marinas, 27(1):139-153.

Serafy, D. K. 1973. Variation in the polytypic sea urchin Lytechinus variegatus (Lamarck, 1816) in the Western Atlantic (Echinodermata; Echinoidea). Bull. mar. Sci., 23(3):525-534.

Tahara, Y.; Okada, M. \& Kobayashi, N. 1960. Further notes on the sexual dimorphisms in Japanese sea urchins. Publ. Seto mar. biol. Lab., 8(1): 183-189, pl. 18-19.

(Manuscript receive 01 November 2001; revised 12 Abril 2002; accepted 25 July 2002) 